\title{
Utilizing perspectives from HIV-infected women, male partners and healthcare providers to design family planning SMS in Kenya: a qualitative study
}

Karren Lewis ${ }^{1}$, Elizabeth K. Harrington², Daniel Matemo ${ }^{3}$, Alison L. Drake ${ }^{1}$, Keshet Ronen ${ }^{1}$, Gabrielle O'Malley ${ }^{1}$, John Kinuthia ${ }^{3}$, Grace John-Stewart ${ }^{1}$ and Jennifer A. Unger ${ }^{1,2^{*}}$ (D)

\begin{abstract}
Background: Short message service (SMS) presents an opportunity to expand the reach of care and improve reproductive health outcomes. SMS could increase family planning (FP) use through education, support and demand generation. The purpose of this analysis is to determine the perspectives of potential FP users to inform design of SMS.

Methods: We conducted focus group discussions (FGD) with HIV-infected women and in-depth interviews (IDI) with male partners and health care workers (HCW) at urban and rural clinics in Kenya to design SMS content for a randomized controlled trial.

Results: Women and men indicated SMS could be used as a tool to discuss FP with their partners, and help decrease misconceptions about FP. Women stated SMS could make them more comfortable discussing sensitive topics with HCWs compared to in-person discussions. However, some women expressed concerns about FP SMS particularly if they used FP covertly or feared partner disapproval of FP use. These findings were common among women who had not disclosed their status. Providers viewed SMS as an important tool for tracking patients and clinical triage in conjunction with routine clinical visits.
\end{abstract}

Conclusion: Our findings suggest that SMS has the potential to facilitate FP education, counselling, and interaction with HCWs around FP.

Keywords: mHealth, Family planning, HIV, SMS

\section{Background}

Providing quality family planning (FP) counselling and service delivery remains a challenge to achieving optimal FP access in Sub-Saharan Africa. This is especially important among HIV-infected women of reproductive age who account for the largest proportion of HIV-infected individuals in Kenya [1]. Integration of FP into HIV services has been successful in improving access to and uptake of FP among HIV-infected individuals [2], and

\footnotetext{
* Correspondence: junger@uw.edu

'Department of Global Health, University of Washington, Seattle, USA

2Department of Obstetrics \& Gynaecology, University of Washington,

Harborview Medical Center, 325 Ninth Ave., Box 359909, Seattle, WA 98104,

USA

Full list of author information is available at the end of the article
}

offers an opportunity to involve partners [3, 4]. However, despite efforts, unmet need for FP remains high; in Kenya, approximately $20 \%$ of HIV-infected women of reproductive age want to stop or delay childbearing but are not using any method of contraception $[5,6]$.

Previous work has shown that HIV-infected women have many of the same concerns about FP as uninfected women including partners' disapproval [7], fertility desires [7] and concerns about side effects [7]. However, they face specific challenges, such as need for dual contraceptive use, prevention of mother to child transmission (PMTCT) [8], and interactions with antiretroviral therapy (ART) $[8,9]$. Research has highlighted the complex contraceptive decision-making of couples

(c) The Author(s). 2019 Open Access This article is distributed under the terms of the Creative Commons Attribution 4.0 International License (http://creativecommons.org/licenses/by/4.0/), which permits unrestricted use, distribution, and reproduction in any medium, provided you give appropriate credit to the original author(s) and the source, provide a link to the Creative Commons license, and indicate if changes were made. The Creative Commons Public Domain Dedication waiver (http://creativecommons.org/publicdomain/zero/1.0/) applies to the data made available in this article, unless otherwise stated. 
affected by HIV [4, 7]. Thus, it is necessary to design novel approaches to FP care delivery for HIV-infected women.

Mobile health (mHealth) interventions present one approach to providing FP counselling and supporting the FP needs of HIV-infected women. mHealth solutions in which patients receive SMS messages from healthcare workers, have been shown to be effective for supplementing clinical care and improving health outcomes [10] and could be beneficial for FP. While mHealth has been widely accepted for appointment reminders and education among HIV-infected populations, [11] integration of FP-related messaging is largely understudied [12]. Studies focusing on FP health promotion or education [13] have demonstrated acceptability and feasibility but have not shown impact on FP use [14]. We aimed to design a culturally appropriate SMS project with input from the end-user community.

We conducted a formative study to inform FP-related SMS content for a randomized controlled trial (RCT) of tailored 1-way SMS versus 2-way SMS dialogue to improve maternal adherence to antiretroviral therapy (ART) (Option $\mathrm{B}+$ ) and retention in care in Kenya [15]. We hypothesize that integrating FP messaging for HIVinfected peripartum women into an SMS strategy for Option $\mathrm{B}+$ would improve integration of clinical care, provide efficiencies in messaging and present a more holistic approach to healthcare for this population, leading to improved outcomes. Our objectives were to investigate perceptions of SMS to support FP use and to design FP-focused SMS messages for the RCT.

\section{Methods}

For the formative phase of an ongoing RCT in Kenya (Mobile WACh-X) [15] participants were recruited from three public sector clinics with an HIV prevalence of 15$19 \%$. This selection of clinics included both rural and periurban settings. Human subject approvals were obtained from the University of Washington and Kenyatta National Hospital, and all study participants provided written informed consent. All interview guides were developed for this study and are available as Additional file 1.

Women were recruited by study staff from perinatal support groups and ANC clinics. Women were purposively sampled to include both pregnant and postpartum women with varying ART experience (Table 1). Female participants completed a sociodemographic survey and were scheduled for a focus group discussion (FGD) at a later date. Two rounds of FGDs, with each focus group containing between 7 and 10 participants, $(N=87$ total participants) took place in each location with groups conducted in English, Swahili and Luo (Fig. 1). Six FGDs took place in the first round and 4. FGDs in the second round. In the first round an experienced facilitator used
Table 1 HIV experience among female FGD participants

\begin{tabular}{|c|c|c|c|}
\hline \multirow[b]{2}{*}{ Site } & \multicolumn{3}{|l|}{ HIV Experience } \\
\hline & $\begin{array}{l}\text { ART outside of } \\
\text { pregnancy }\end{array}$ & $\begin{array}{l}\text { ART for PMTCT } \\
\text { only }\end{array}$ & $\begin{array}{l}\text { No prior ART } \\
\text { experience }\end{array}$ \\
\hline $\begin{array}{l}\text { Rural } \\
\text { site } 1\end{array}$ & 14 & 5 & 5 \\
\hline $\begin{array}{l}\text { A rural } \\
\text { site }\end{array}$ & 24 & 0 & 1 \\
\hline Mathare & 22 & 14 & 2 \\
\hline Total & 60 & 19 & 8 \\
\hline
\end{tabular}

a semi-structured guide developed for this study (sumplementary files) to address topics such as challenges in care utilization, medication adherence, and FP. She also explored themes for additional messaging concerns, such as security and message sharing. The facilitator distributed example SMS, some containing FP messaging, developed for this intervention, to elicit feedback and facilitate discussion. SMS messages were refined following round 1 , and in round 2 , the facilitator presented new SMS to explore comprehension, acceptability and further refine content.

Male participants were recruited through female FGD participants and by study staff who recruited men with HIV-infected female partners from each study site ( 5 men per site, $N=15$ ). Men completed a sociodemographic survey and interviews were conducted by the same facilitator addressed: SMS comprehension and acceptability, involvement of male partners in SMS programs primarily targeting women, potential use and acceptability of SMS to discuss sensitive topics such as HIV and FP, and general concerns about SMS communication.

Health care providers, including nursing officers, maternal child health $(\mathrm{MCH})$ nurses, clinical officers, pharmacists and peer counsellors, were recruited to participate and given a survey prior to an in-depth interview (IDI). Each site enrolled 10 providers $(N=30)$. IDI topics discussed included: current provider challenges to $\mathrm{HIV}$ and $\mathrm{MCH}$ care; and perceived potential for SMS to improve clinic attendance, retention in care, HIV education, and communication of sensitive topics such as FP.

Interviews were transcribed from audio recordings and translated into English when necessary. Transcripts and survey data were analysed in Dedoose (Los Angeles, CA) [16]. Two investigators (KL and $\mathrm{EH})$ coded each set of transcripts. After independently reading transcripts, they developed an initial list of codes for each transcript set. Preliminary codebooks, along with an open coding process to incorporate emerging thematic codes, were used to code five transcripts in each set; EH and KL then compared codes and developed revised codebooks for 


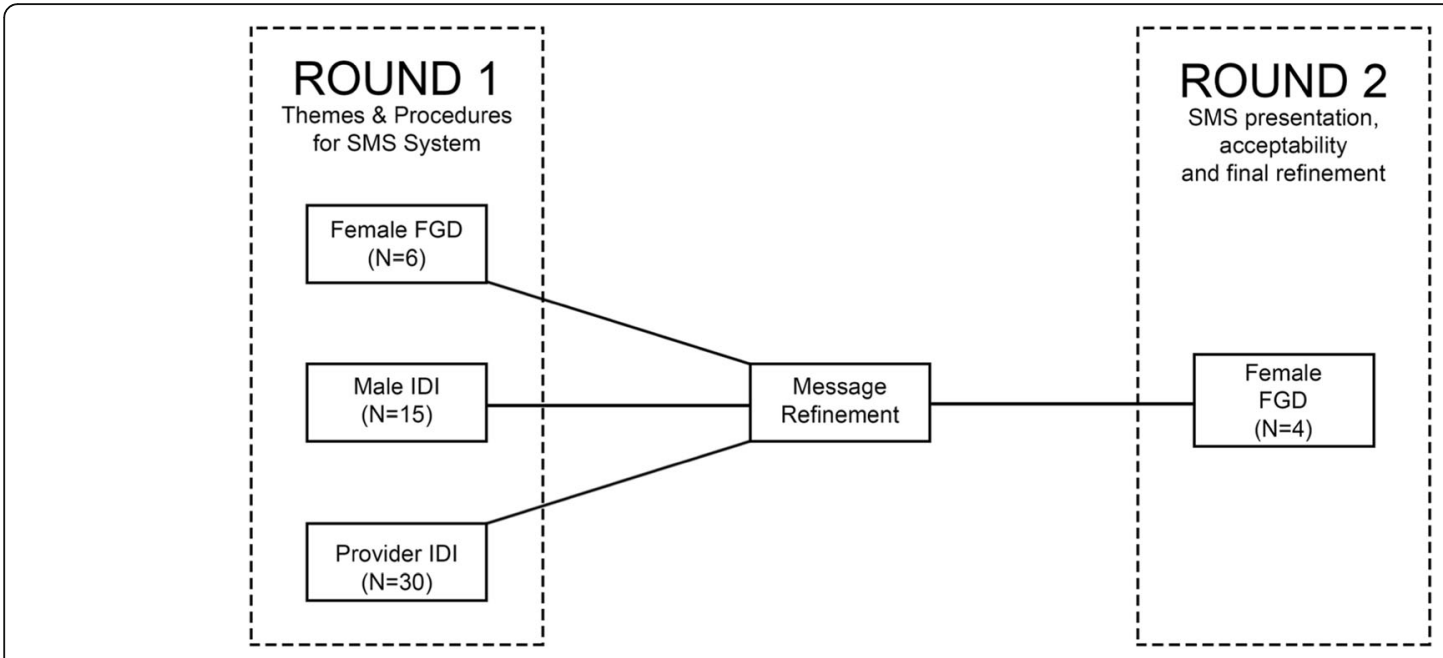

Fig. 1 Schematic of formative phase interviews and message refinement

each set of transcripts. The final codebook was reviewed with a senior qualitative expert (GO). All transcripts were then coded or re-coded, and EH and KL met to compare code application and consistency, and reach consensus. Textual data was then grouped by code and transcript set to allow for comparing and contrasting themes across FGDs and IDIs to emerge. Overarching themes were synthesized into memos or thematic summaries. Memos were then reviewed by members of the Mobile WACh X team to refine emerging concepts.

\section{Results}

Female FGD participants $(n=87)$ had a median age 26 years (interquartile range [IQR]: $23-31.5$ years), were predominantly in monogamous partnerships (66\%), and most had children (93\%). The majority (74\%) completed primary education, and most (91\%) had experience with
ART/PMTCT. Median age of men $(n=15)$ was 37 years (IQR 33-43 years) and most (93\%) lived with their current partner. The majority $(73 \%)$ of men received at least some primary education and reported as HIVinfected $(80 \%)$; all HIV-infected men had prior or current ART experience. Health care providers $(n=30)$ had a median of 6 years in clinical practice (IQR: 4-15 years) (Table 2).

Both women and men generally favored SMS as a strategy to improve knowledge, dispel myths and empower women to initiate FP. A married woman, aged 20-24, from a rural site said, '[If] you send SMS I can know that family planning is good for my health: especially now that I know my status I should plan my family.' Since SMS messages could be shared with male partners, many women felt FP-related SMS could be a tool to educate partners about FP options, and help

Table 2 Participant Characteristics

\begin{tabular}{|c|c|c|c|}
\hline & Women $(n=87)$ & Men $(n=15)$ & Providers $(n=30)$ \\
\hline \multicolumn{4}{|l|}{ Site } \\
\hline Rural site 1 & 24 & 5 & 10 \\
\hline Rural site 2 & 26 & 5 & 10 \\
\hline Mathare & 37 & 5 & 10 \\
\hline \multicolumn{4}{|l|}{ Demographics } \\
\hline Age median, years, (IQR) & $26(23-32)$ & $37(33-43)$ & $36(31-43)$ \\
\hline In relationship = n (\%) & $75(86)$ & $15(100)$ & $28(93)$ \\
\hline Married n (\%) & $70(80)$ & & $27(90)$ \\
\hline \multicolumn{4}{|l|}{ Education n (\%) } \\
\hline Less than primary & $23(26)$ & $3(20)$ & \\
\hline At least primary & $43(49)$ & $8(53)$ & \\
\hline Secondary or above & $20(23)$ & $4(27)$ & \\
\hline Pregnant & $30(34)$ & & \\
\hline
\end{tabular}


dispel common FP misperceptions for both partners. A married 35-39 year old woman from a rural site said, '[If] you want to use family planning, then you should educate yourselves with your husband so that none of you gets surprised'. Women said it would be important for both partners to receive SMS messages on women's health because they could help clarify recommendations from clinic visits for FP decision-making.

I think it [SMS] can be sent because it is good even the spouse would understand it [IUCD], it is easy to put, it takes many years, it easy to remove and at any time it is good if he sees that it can be removed easily (married woman (age 30-34), rural site).

Women also noted that SMS offered a level of anonymity that could help overcome barriers to discussing sensitive topics like FP:Sending messages can be easier to tell my story. Some things are difficult to just face someone and tell them, like you can find it hard to tell the doctor that your husband has refused to use condoms ... Even if you have problems with your breast or private parts you will have problems telling the doctor of opposite sex, but through SMS you can tell him ... and you will get help (married woman (age 20-24), urban site).

Male participants echoed the sentiments about the potential for SMS to educate and dispel FP myths, and described how messaging could help change men's opinions. Several men described the need for repeated delivery of health information to help them overcome widespread misperceptions.[My] wife has been encouraging me about family planning ... but I have not understood ... SMS which encourages family planning should be sent to me also to read ... I will eventually understand it and agree to it (HIV-infected male (age 25-29), rural site).

Women who reported disclosing their HIV status to partners were more interested in detailed SMS that could be both educational and supportive to them and their partners. Several described the act of disclosure as a gateway to increased communication about health topics. A married woman, aged 25-29, from the urban site said, 'I had not disclosed to my husband, so I was just hiding ... One day ... he saw the drugs. He took it and read, so I just told him [and] I started to cry. But he understood and we went together and got tested.' The importance of openness and communication within couples was repeatedly mentioned in relation to discussions about FP messaging. Some women felt that HIV disclosure and discussion of FP were mutually reinforcing:[If] my husband [knows] my status then he will be the first person to advise me to go for family planning. (married woman (age 20-24, rural site).

Although most participants appreciated the potential for SMS to support FP, partner HIV status disclosure figured prominently in relation to women's opinions about SMS for FP. Women who had not disclosed their HIV status were generally not comfortable receiving SMS with overt messaging about HIV or FP, and tended to express a higher level of concern about the SMS content. Women mentioned various consequences of unintended HIV disclosure, such as physical abuse, relationship dissolution, and loss of financial support. Several women described using ART without the knowledge of their male partners, and concerns about concealed FP use being discovered as a result of partners reading FP-related SMS on their phones.

Most] men have not embraced family planning, in that case if he receives the message and reacts badly then it will mean that he hasn't been told about ... family planning, since most men do not like family [planning] ... if you use it secretly it might affect you (married woman, (age 25-29) urban site).

Women felt strongly about obtaining permission prior to sending FP messaging, in order to help protect privacy. A married woman, age 25-29, from a rural site said, 'Some men have issues with family planning, and they don't allow their wives to use it, so ... you use it in secret ... I think that it [FP-related SMS messages] can be sent to someone who has consented.'

Overall, men showed a strong interest in being included in FP-related SMS messaging as part of a clinicbased intervention. However, some men articulated concerns about FP messages causing problems for women in the community whose partners had misperceptions about FP including female infidelity. One man said:

There are some men who don't want anything to do with family planning, so when you want to send SMS you have to try as hard as possible for them [women] to share ideas about family planning with their husbands so that they get to a point where the husband knows what it is all about (HIV-infected male (age 25-29), rural site).

Participants identified limitations to sending FP-related SMS, but an especially important one for providers was the inability of SMS to deliver counselling on complex topics and to deliver FP services. Both women and providers said SMS could not replace attending clinic, indepth counselling and determining medical eligibility.[No] we cannot use another SMS to counsel; because 
she has to be there in person ... [The] mother has to come to the hospital [to] check the weight and blood pressure. She cannot just come and it [implant] is inserted, she has to undergo examination before it is inserted ( $\mathrm{MCH}$ nurse (age 55-59), rural site).

Several health care providers expressed concern about confidentiality and covert FP use with use of SMS. A mentor mother, age 45-49, in the urban site said, 'I don't want you to mention ... the kinds of family planning practice because these clients don't want [their] partner to know what it is ... they use the family planning without even telling the partner.' They also noted that women should have to consent to receiving FPrelated messages.

Providers described several ways in which SMS could improve clinic flow and clinical care in general. First, they felt it was an important way to remind women about appointments and track missed visits. Additionally, SMS were thought to act as a mechanism to triage complaints and avoid unnecessary visits to clinic.

I think the provider workload will reduce, because some of them come to the clinic specifically because they have some questions ... 'When do I start family planning?' ... You can just SMS and tell the lady, 'don't come this time it is not yet'...instead of wasting time to come here (nurse (age 20-24), rural site).

\section{Discussion}

This study explores the perspectives of key stakeholders, including HIV-infected women, male partners, and health care providers, on the utility of SMS for FP education and support. Unmet need for family planning among HIV-infected women in Kenya remains high, making innovative strategies to reach this population a high priority [1]. We identified important considerations for the development of SMS programs tailored for HIVinfected women in the setting of an mHealth intervention focusing on Option B+/lifelong ART adherence.

Experience with HIV disclosure was a strong determinant of women's desire for messaging with HIV or FP-related content. Previous studies support the potential for HIV disclosure to lead to improved communication about HIV and other health topics within sexual relationships [17]. Furthermore, HIV disclosure is postulated to have important effects on health care outcomes; specifically, non-disclosure has been associated with poorer PMTCT outcomes [18], likely due to limitations on health-seeking behaviours. In our study, women who had not disclosed their HIV status had concerns not only about HIV-related messaging, but also about receiving SMS with FP content. While HIV disclosure may open the door to couple communication about other sensitive topics, it is also possible that women in more gender-equitable relationships are more comfortable talking with partners about these topics, including HIV and FP. A qualitative study of couples in Kenya supports this idea that couple communication and trust are prerequisites for HIV disclosure [19]. As communication and power dynamics within couples influence women's comfort with, and participation in, mHealth programs, these complex issues need to be considered in SMS development and how mHealth interventions are advertised to women.

Although SMS interventions have demonstrated benefits in HIV care outcomes [10] as well as uptake of $\mathrm{MCH}$ care [20], there is also potential for harm by inadvertent disclosure of personal information through SMS. Messaging interventions targeting health outcomes in low-resource settings often employ a "one size fits all" approach $[10,14,21]$. Our data suggest that programs directed towards women accessing HIV and RHFP information should include tailored options to elect the type of messages they want to receive, and provide clear communication about the content of messages, especially in the context of phone sharing. As a result of this formative work, we implemented example message demonstrations as part of the study introduction and consent process. In addition, we added a transition SMS message which informed women about and introduced the subsequent FP messaging that would follow. The introduction message read "Over the next few weeks we will send you messages to help you make family planning decisions. Planning your family and spacing pregnancy is good for your health." In this way, women were aware that the next few messages would be counselling about FP.

Within heterosexual relationships, it is important to consider the role of men in FP decision making. Previous research in the region suggests that FP education in the clinical setting may not be an ideal way to shift male resistance to FP [22], and community-based interventions, which may include SMS, may be a more viable option. Our findings highlight varying perspectives among HIV-infected women regarding men's response to FPrelated messaging. Most women and men perceived benefits to sharing FP-related SMS with partners, and felt male partners should be included in SMS programs. Most participants viewed SMS as an acceptable method to engage men and prior studies demonstrate the importance of male inclusion in FP discussions for successful FP programs [3, 23]. As a result we did include messages about speaking to partners about family planning. An example of this type of message read: "Spacing your pregnancies keeps you and your family healthy. Partners are sometimes against family planning or do not have enough information. If you feel comfortable, 
please share the messages with your partner. Family planning is very safe. Return to fertilty is very quick with most methods! Are you using family planning? Is your partner supportive?". Yet, a small number of women had concerns about potential negative effects, indicating that this approach is not universally acceptable.

In addition, SMS may help improve patient-provider relationships and increase clinic efficiency. As in other studies, interviews with healthcare workers demonstrated interest in using SMS for ART adherence support and appointment tracking [24], triaging patient complaints, and improving patient-provider communication. SMS may also be able to alleviate fears women have about talking to providers in person due to previous experiences with mistreatment [25] or concerns discussing sensitive topics. While many benefits of SMS were articulated by participants, healthcare providers and women both stressed the necessity for clinic-based counselling and inability of SMS to replace clinical services.

As program implementers increasingly recognize the promise of SMS in education and behaviour change, and mHealth programs utilizing SMS grow in number, this study's findings support the need to elucidate community desires and concerns prior to roll-out. This formative work informed the design and content of FP messaging, and more broadly, altered our approach to the study consent process regarding HIV messaging [26]. Women in the associated RCT have more control over what types of HIV-related messages they choose to receive.

Our study has some limitations. As an exploratory qualitative study focused on HIV-infected women, our results may not be generalizable to other populations. FP-related experiences and concerns among HIVinfected women may differ from those with unknown or HIV negative status. In addition, views and experiences of women engaged in HIV care may not reflect the views from people not involved in care. Men in this study were primarily recruited via referral from female partners, which may bias the results towards male support for FPrelated messaging.

\section{Conclusion}

This study provides insight into the perspectives of HIVinfected women, men, and providers on an SMS approach to FP education, and emphasizes the need for community input during development of mHealth programs. Without appropriate formative work, programs might inadvertently send FP or HIV-related messaging that place women at risk-or contribute to conflict within couples. Our study demonstrated SMS is an acceptable approach to delivering FP education. However, community context and social acceptability of SMS topics must be identified and appropriate consent obtained, if applicable. In many settings, designing programs to include both women and men may be beneficial. SMS appears to be an acceptable bridge to improve communication between patients and providers; further research is needed to determine if SMS interventions can lead to improved FP uptake and explore impact on FP-related communication between women and their partners.

\section{Supplementary information}

Supplementary information accompanies this paper at https://doi.org/10. 1186/s12913-019-4708-7.

Additional file 1. Focus group discussion guides.

\section{Abbreviations}

ART: Antiretroviral therapy; FGD: Focus group discussion; FP: Family planning; HCW: Health care worker; IDI: In-depth interview; MCH: Maternal child health; mHealth: Mobile health; PMTCT: Prevention of mother to child transmission; $\mathrm{RCT}$ : Randomized controlled trial; SMS: Short message service

\section{Acknowledgements}

This research received administrative support and mentorship from the Global Center for Integrated Health of Women, Adolescents and Children (Global WACh), which is jointly-supported by the Departments of Global Health, Pediatrics, and Obstetrics and Gynecology. We are grateful to the Kizazi group of the Global Center for Integrated Health of Women, Adolescents and Children (Global WACh), which provided feedback on study design.

\section{Authors' contributions}

DM, ALD, KR, GO, JK, and JAU made a substantial contribution to the design of the study. DM, ALD, KR, JK, GJS and JAU were responsible for the implementation of the study and acquisition of the data. EKH, GJS and JAU were responsible for overall supervision. $\mathrm{KL}$, EKH and JAU performed the analysis and interpretation of the data. $\mathrm{KL}, \mathrm{EKH}$ and JAU wrote the initial draft of the manuscript. All other authors provided significant feedback on the manuscript drafts. All authors agree to be accountable for the work. All authors read and approved the final manuscript.

\section{Funding}

Funding was provided by the National Institutes of Health (K12HD001264 to JAU, R01HD080460, K24HD054314 and to GJS, K01Al116298 to ALD). The funder had no role in the design, collection, analysis and interpretation of the data.

Availability of data and materials

The data sets used and analysed during the current study are available from the corresponding author upon request.

Ethics approval and consent to participate

Institutional Review Board approval for this study and the consent forms associated with the study was obtained from the University of Washington (42621) on 6/6/2013 and the Kenyatta National Hospital/University of Nairobi Ethics Review Committee (ERC) (P310/06/2012) on 9/21/2012. All particpants participated in the informed consent process and provided written consent.

Consent for publication

Not applicable.

Competing interests

The authors declare that they have no competing interests.

\section{Author details}

${ }^{1}$ Department of Global Health, University of Washington, Seattle, USA. ${ }^{2}$ Department of Obstetrics \& Gynaecology, University of Washington, Harborview Medical Center, 325 Ninth Ave., Box 359909, Seattle, WA 98104, 
USA. ${ }^{3}$ Department of Research and Programs, Kenyatta National Hospital, Nairobi, Kenya.

Received: 13 February 2019 Accepted: 5 November 2019

Published online: 21 November 2019

\section{References}

1. National AIDS and STI Control Programme (NASCOP). Kenya AIDS Indicator Survey 2012: Final Report. Nairobi: NASCOP; 2014. p. 1-530. https://doi.org/ 10.1097/QAl.0000000000000152

2. Lopez LM, Grey TW, Chen M, Denison J, Stuart G. Behavioral interventions for improving contraceptive use among women living with HIV. Cochrane Database Syst Rev. 2016;8:CD010243. https://doi.org/10.1002/14651858. CD010243.pub3.

3. Newmann SJ, Grossman D, Blat C, Onono M, Steinfeld R, Bukusi EA, et al. Does integrating family planning into HIV care and treatment impact intention to use contraception? Patient perspectives from HIV-infected individuals in Nyanza Province, Kenya. Int J Gynecol Obstet. 2013;123:e1623. https://doi.org/10.1016/j.ijgo.2013.08.001.

4. Harrington EK, Dworkin S, Withers M, Onono M, Kwena Z, Newmann SJ. Gendered power dynamics and women's negotiation of family planning in a high HIV prevalence setting: a qualitative study of couples in western Kenya. Cult Health Sex. 2015;1058:1-17. https://doi.org/10.1080/13691058. 2015.1091507.

5. Kenya National Bureau of Statistics, ICF Macro. Kenya Demographic and Health Survey 2014. Nairobi, Rockville: ICF International; 2015.

6. Obare F, Birungi H, Undie C, Wanjiru M, Liambila W, Askew I. Levels, trends and determinants of contraceptive use among adolescent girls in Kenya. Nairobi: APHIA II OR Project in Kenya/Population Council; 2011.

7. Wanyenze RK, Wagner GJ, Tumwesigye NM, Nannyonga M, WabwireMangen F, Kamya MR. Fertility and contraceptive decision-making and support for HIV infected individuals: client and provider experiences and perceptions at two HIV clinics in Uganda. BMC Public Health. 2013;13:98. https://doi.org/10.1186/1471-2458-13-98.

8. Laher F, Todd CS, Stibich MA, Phofa R, Behane X, Mohapi L, et al. A qualitative assessment of decisions affecting contraceptive utilization and fertility intentions among HIV-positive women in Soweto, South Africa. AIDS Behav. 2009;13:47-54. https://doi.org/10.1007/s10461-009-9544-z.

9. Todd CS, Stibich MA, Laher F, Malta MS, Bastos Fl, Imbuki K, et al. Influence of culture on contraceptive utilization among HIV-positive women in Brazil, Kenya, and South Africa. AIDS Behav. 2011:15:454-68. https://doi.org/10. 1007/s10461-010-9848-z.

10. Lester RT, Ritvo P, Mills EJ, Kariri A, Karanja S, Chung MH, et al. Effects of a mobile phone short message service on antiretroviral treatment adherence in Kenya (WelTel Kenya1): a randomised trial. Lancet. 2010;376:1838-45. https://doi.org/10.1016/S0140-6736(10)61997-6.

11. Jennings $L$, Ong'ech J, Simiyu R, Sirengo M, Kassaye S. Exploring the use of mobile phone technology for the enhancement of the prevention of mother-to-child transmission of HIV program in Nyanza, Kenya: a qualitative study. BMC Public Health. 2013:13:1131. https://doi. org/10.1186/1471-2458-13-1131.

12. Smith C, Gold J, Ngo T, Sumpter C, Free C. Mobile phone-based interventions for improving contraception use. Cochrane Database Syst Rev. 2015. https://doi.org/10.1002/14651858.CD011159.pub2 www. cochranelibrary.com

13. Ippoliti NB, Engle KL. Meet us on the phone: mobile phone programs for adolescent sexual and reproductive health in low-to-middle income countries. Reprod Health. 2017;14:1-8. https://doi.org/10.1186/s12978016-0276-z.

14. Johnson D, Juras R, Riley P, Chatterji M, Sloane P. A randomized controlled trial of the impact of a family planning mHealth service on knowledge and use of contraception. Contraception. 2017;95:90-7. https://doi.org/10.1016/j. contraception.2016.07.009.

15. Drake AL, Unger JA, Ronen K, Perrier T, Derenzi B, Richardson BA, et al. Evaluation of mHealth strategies to optimize adherence and efficacy of option B + prevention of mother-to-child HIV transmission: rationale, design and methods of a 3-armed randomized controlled trial. Contemp Clin Trials. 2017. https://doi.org/10.1016/j.cct.2017.03.007.

16. Dedoose Version 7.5.17. Web application for managing, analyzing, and presenting qualitative and mixed method research data 2017.
17. Maman S, Medley A. Gender dimensions of HIV status disclosure to sexual partners - rates barriers and outcomes: a review paper. Geneva: World Health Organization; 2003.

18. Jasseron C, Mandelbrot L, Dolfus C, Trocmé N, Tubiana R, Teglas JP, et al. Non-disclosure of a pregnant woman's HIV status to her partner is associated with non-optimal prevention of mother-to-child transmission. AIDS Behav. 2013;17:488-97. https://doi.org/10.1007/s10461-011-0084-y.

19. Rogers AJ, Achiro L, Bukusi EA, Hatcher AM, Kwena Z, Musoke PL, et al. Couple interdependence impacts HIV-related health behaviours among pregnant couples in southwestern Kenya: a qualitative analysis. J Int AIDS Soc. 2016:19:1-10. https://doi.org/10.7448//AS.19.1.21224

20. Lee SH, Nurmatov UB, Nwaru Bl, Mukherjee M, Grant L, Pagliari C. Effectiveness of mHealth interventions for maternal, newborn and child health in low- and middle-income countries: systematic review and metaanalysis. J Glob Health. 2016;6:010401. https://doi.org/10.7189/jogh.06. 010401

21. Barron P, Pillay Y, Fernandes A, Sebidi J, Allen R. The MomConnect mHealth initiative in South Africa: early impact on the supply side of $\mathrm{MCH}$ services. J Public Health Policy. 2016;37:201-12. https://doi.org/10.1057/s41271-0160015-2.

22. Withers M, Dworkin S, Onono M, Oyier B, Cohen C, Bukusi E, et al. Men's perspectives on their role in family planning in Nyanza Province, Kenya. Stud Fam Plann. 2015;46:201-15. https://doi.org/10.1111/j.1728-4465.2015. 00024.x.

23. Hartmann M, Gilles K, Shattuck D, Kerner B, Guest G. Changes in couples' communication as a result of a male-involvement family planning intervention. J Health Commun. 2012;17:802-19. https://doi.org/10.1080/ 10810730.2011 .650825

24. Mushamiri I, Luo C, liams-Hauser C, Ben AY. Evaluation of the impact of a mobile health system on adherence to antenatal and postnatal care and prevention of mother-to-child transmission of HIV programs in Kenya. BMC Public Health. 2015;15:102. https://doi.org/10.1186/s12889-015-1358-5.

25. Turan JM, Miller S, Bukusi EA, Sande J, Cohen CR. HIV/AIDS and maternity care in Kenya: how fears of stigma and discrimination affect uptake and provision of labor and delivery services. AIDS Care. 2008;20:938-45. https:// doi.org/10.1080/09540120701767224

26. Fairbanks J, Beima-Sofie K, Akinyi P. Matemo D, Unger JA, Kinuthia J, et al. You will know that despite being HIV positive that you are not alone: Qualitaitve study to inform content of a text messaging intervention to improve prevention of mother-to-child HIV transmission. JMIR Mhealth Uhealth. 2018;6(7):e10671. https://doi.org/10.2196/10671.

\section{Publisher's Note}

Springer Nature remains neutral with regard to jurisdictional claims in published maps and institutional affiliations.

Ready to submit your research? Choose BMC and benefit from:

- fast, convenient online submission

- thorough peer review by experienced researchers in your field

- rapid publication on acceptance

- support for research data, including large and complex data types

- gold Open Access which fosters wider collaboration and increased citations

- maximum visibility for your research: over $100 \mathrm{M}$ website views per year

At BMC, research is always in progress.

Learn more biomedcentral.com/submissions 